\title{
Depression, Anxiety, and Stress Symptoms and Its Associated Factors Among Residents of Gondar Town During the Early Stage of COVID-19 Pandemic
}

This article was published in the following Dove Press journal:

Risk Management and Healthcare Policy

Temesgen Yihunie Akalu (D) Kassahun Alemu Gelaye (D) Mulat Addis Bishaw $\mathbb{D}^{2}$ Sewbesew Yitayih Tilahun ${ }^{3}$ Yigizie Yeshaw (iD ${ }^{4}$

Telake Azale ${ }^{5}$

Tewodros Tsegaye (D) $^{2}$

Daniel Asmelash (iD)

Yonas Akalu (iD)

'Department of Epidemiology and Biostatistics, Institute of Public Health, University of Gondar, Gondar, Ethiopia ${ }^{2}$ Department of Internal Medicine, College of Medicine and Health Sciences, University of Gondar, Gondar, Ethiopia; ${ }^{3}$ Department of Psychiatry, School of Medicine, College of Medicine and Health Sciences, University of Gondar, Gondar, Ethiopia; ${ }^{4}$ Department of Human Physiology, School of Medicine, College of Medicine and Health Science, University of Gondar, Gondar, Ethiopia; ${ }^{5}$ Department of Health Education and Behavioral Science, Institute of Public Health, University of Gondar, Gondar, Ethiopia; ${ }^{6}$ Department of Clinical Chemistry, School of Biomedical and Laboratory Sciences, College of Medicine and Health Sciences, University of Gondar, Gondar, Ethiopia

Correspondence: Temesgen Yihunie Akalu

Department of Epidemiology and Biostatistics, Institute of Public Health, University of Gondar, PO.Box: 196,

Gondar, Ethiopia

Tel +251929390709

Email temesgenyihunie@gmail.com
Purpose: An acute respiratory disease caused by the novel coronavirus disease (COVID) was identified in late 2019. COVID-19 triggered a wide range of psychological problems, such as anxiety, depression, and stress. However, studies on mental health status in developing countries including Ethiopia related to COVID-19 are very limited. Therefore, this study was aimed at determining the magnitude of depression, anxiety, and stress, and their associated factors among Gondar town population during the early stage of the COVID-19 pandemic.

Patients and Methods: A community-based cross-sectional study was conducted among 660 residents of Gondar town in April 2020. A multi-stage sampling technique was employed to select study participants. A 21 item depression, anxiety, and stress scale (DASS-21) was used. Variables with a $p$-value $<0.05$ in the final model were declared as statistically significant. Hosmer and Lemeshow goodness of fit test was used to check the model fitness.

Results: In this study, the prevalence of depression was $32.0 \%$ (95\% CI: 28.4-35.5), anxiety $25.8 \%$ (95\% CI: $22.4-29.1$ ), and stress $14.7 \%$ (95\% CI: $12.0-17.4)$, respectively. The odds of developing depression was higher among female respondents ( $\mathrm{AOR}=2.30,95 \% \mathrm{CI}$ : 1.01 , 3.83 ) and ever smokers ( $\mathrm{AOR}=2.8,95 \mathrm{CI}: 1.23,6.28)$ as compared to their counterparts. Besides, history of medical illness and ever smoking increase the odds of anxiety by 2.3 $(\mathrm{AOR}=2.3 ; 95 \% \mathrm{CI}: 1.42-3.76)$, and 2.8 (AOR=2.8; 95\% CI: 1.23-3.83), respectively. Furthermore, being unemployed and family size of $<5$ increase the odds of stress by 2.1 $(\mathrm{AOR}=2.1$; 95\% CI: 1.17-3.83) and $1.8(\mathrm{AOR}=1.8$; 95\% CI: 1.09-2.81), respectively.

Conclusion: In this study, the overall depression, anxiety, and stress were significantly high. There are number of factors associated with depression, anxiety, and stress. Designing and implementing tailored strategies for COVID-19 prevention and control could be supremely important to reduce mental health problems in the community.

Keywords: depression, anxiety, stress, COVID-19, Gondar

\section{Background}

The Coronavirus Disease 2019 (COVID-19) has emerged in Wuhan city, Hubei province of China, spread nationwide alarmingly on top of half a dozen in other countries between December 2019 and early 2020. ${ }^{1}$ On March 11, 2020, the World Health Organization (WHO) declared COVID-19 as a global pandemic disease and call for countries to work jointly and coordinate international responses towards the disease. ${ }^{2}$ 
According to Johns Hopkins University report, as of July 31 , there are $17,600,740$ cases and 679,600 deaths with $10,342,311$ recoveries of COVID-19 globally. ${ }^{3}$ In the time of the outbreak, individuals are commonly stressed and worried ${ }^{4}$ and resulted in an economic crisis. $^{5}$ Since COVID-19 is an emerging suddenly and highly infectious, it causes serious threats to peoples' physical health and lives. Besides, data from different countries highlighted that the COVID-19 outbreak and associated quarantine measures negatively affect mental health and triggered a wide variety of psychological problems and increase symptoms of psychological distress such as anxiety, depression, suicidal attempts and post-traumatic stress among the general population. ${ }^{6-8}$ The stressful conditions of COVID-19 pandemic also lead to psychological distress and clinical worsening of affective symptoms in individuals with mental disorders. ${ }^{9}$ According to the recent meta-analysis, the prevalence of depression, anxiety and stress during COVID-19 pandemic was $33.7 \%, 31.9 \%$, and $29.6 \%$, respectively. ${ }^{10}$

A study done in China among the general population during the COVID-19 pandemic reported that $35.1 \%$ of the study participants had Generalized Anxiety Disorder (GAD-7), and 20.1\% had depressive symptoms. ${ }^{11}$ Another report in Spain during the early phase of the COVID-19 pandemic identified that $36 \%$ of the study participants had moderate to severe psychological problems; of which $25 \%$ had a mild to severe anxiety, $41 \%$ had depression and $41 \%$ had stress symptoms. ${ }^{12}$

During the COVID-19 pandemic, younger age and being female were associated with the higher prevalence of psychological distress symptoms like depression and anxiety. ${ }^{13}$ Socioeconomic status, early childhood trauma, conducting leisure activities, sex, age, job status, and the perception of being in good health were factors associated with mental health outcomes. ${ }^{12,14}$ Studies in Italy showed that the higher number of lockdown days, living alone during the lockdown, smoking habits, and long duration of illness during the acute phase of COVID-19 pandemic were associated with a higher prevalence of psychological distress and post-traumatic stress symptoms. ${ }^{14-16}$ Biological factors like low serum vitamin-D were also found to be associated with higher psychological distress in patients with mood disorders during the COVID-19 outbreak. ${ }^{9}$

Even though countries across the globe design different strategies including full/partial lockdown, social distancing measures, closure of schools, cancelation of public gatherings, and use of a mask to control the spread of the pandemic and to minimize the catastrophic effect of COVID-19, the spread of the pandemic and its disastrous effect is become worsen. However, studies on mental health status in developing countries like Ethiopia are very limited. Hence, understanding and investigating public psychological problems during this tumultuous time has practical significance. Therefore, this study aimed to determine the magnitude of depression, anxiety, and stress, and their associated factors among Gondar town residents' during the early stage of the COVID-19 pandemic. Policymakers, health care planners, medical practitioners, and other concerned bodies might use the information from this study to develop a diagnosis, treatment, and preventive strategies of COVID 19 induced depression, anxiety, and stress.

\section{Methods}

\section{Study Design, Area, and Period}

A community-based cross-sectional study was conducted in April 2020. This study was conducted in Gondar town, located $728 \mathrm{~km}$ far from Addis Ababa, and the capital city of Ethiopia. According to the 2018 population projection, the estimated population size is 430,178 . It is subdivided into 12 sub-cites. The town has 24 kebeles, the smallest administrative units in the country. According to the town's health office report of 2018, the town has 1 referral hospital, 8 government health centers, and 14 health posts (the lowest health care unit in Ethiopian health care system). On the other hand, there is 1 primary hospital, 41 different level clinics, one international laboratory, and 23 pharmacy units and drug stores owned by private sectors.

\section{Population and Sample}

All adults ( $\geq 18$ years) who were volunteers to participate after informed consent was given have participated. The sample size was calculated using a single population proportion formula based on a previous study from China ${ }^{17}$ using the following assumptions: $95 \%$ confidence level, and $\alpha=$ level of significance (5\%), and margin of error (d) $=0.05$, design effect of 2 , and non-response $10 \%$. The sample was calculated using Epi-info version 7 and the maximum sample size used in this study was 693 . From 20 kebeles of Gondar town, 6 kebeles were selected randomly using the lottery method. A multi-stage sampling technique was employed (Table 1). 
Table I Sample Size Calculation Using Epi-Info Version 7

\begin{tabular}{|l|l|l|}
\hline Variable & Prevalence & $\begin{array}{l}\text { Sample Size (Including } \\
\text { Non-Response and Design Effect) }\end{array}$ \\
\hline Depression & 16.5 & 466 \\
\hline Anxiety & 28.8 & 693 \\
\hline Stress & 8.1 & 228 \\
\hline
\end{tabular}

\section{Variable of the Study}

In this study, the outcome variables were the presence or absence of symptoms of depression, anxiety, and stress. Independent variables include socio-demographic characteristics: age, sex, educational status, religion, marital status, occupation, family size, and the number of people with close contact, clinical factors: history of medical and known mental illness, and behavioral factors: ever alcohol drinking, current alcohol drinking, ever cigarette smoking, current cigarette smoking, ever chat chewing, and current chat chewing.

A modified version of the self-reported Depression Anxiety, and Stress Scale (DASS) that contains 21 items was used to measure depression, anxiety, and stress. Each domain comprises 7 items assessing symptoms of depression, anxiety, and stress. These items include, for example, for depression: "I found it difficult to work up the initiative to do things"; for anxiety: "I experienced trembling"; and for stress: "I tended to over-react to situations". Participants were asked to indicate the presence of symptoms in each domain over the past week and responses ranged from 0 to 3 with 0 indicating "did not apply to me at all"; 1 indicating "applied to me to some degree, or some of the time"; 2 indicating "applied to me to a considerable degree or a good part of the time", and 3 indicating "applied to me very much or most of the time". The tool has 21 items, 3 subscales of 7 items for each outcome variables: depression, anxiety and stress. Therefore, each outcome variables has 7 questions. Because the DASS 21 is a short form version of the DASS 42 items, the final score of each outcome variable: Depression, Anxiety and Stress were multiplied by two (x2), and then categorized according to the DASS manual as normal, mild, moderate, severe, and extremely severe. The individual item scores range from a minimum of 0 to a maximum of 42 . A higher score indicates a greater level of depression, anxiety, and stress. Accordingly, depression score of $0-9$ was considered as normal, 10-13 as mild, 14-20 as moderate, 21-27 as severe, and 28 and above as extremely severe depression. For anxiety, participants with anxiety score of $0-7$ was considered as normal, 8-9 as mild, $10-14$ as moderate, $15-19$ as severe, and 20 and above as extremely severe. For the case of stress, stress score of 0-14 were considered as normal, 15-18 as mild, $19-25$ as moderate, $26-33$ as severe, and 34 and above as extremely severe. ${ }^{18}$

Chronic medical illness was defined as those respondents who had at least one chronic illness that is diagnosed before from any private and public health institution and currently on follow up. Past mental illness was defined as a respondent who was previously diagnosed with mental illness and treated in the past or currently on treatment. Current use was defined as use of alcohol, chat, and/or cigarette in the last three months. Ever use was defined as use of alcohol, chat, and/or cigarette even once in one's lifetime. ${ }^{19}$

\section{Data Collection Instrument and Quality Control}

English version standardized questionnaires DASS-21 was prepared initially and translated to local language (Amharic) then back to English to ensure its consistency. The interviewer-administered method was applied to collect the data. A total of 11 Bachelor of Science (BSC) psychiatry and professional nurses were recruited to collect the data. Five individuals were assigned as a supervisor in controlling the overall data collection process. The training was given for data collectors and supervisors. The pre-test was done on $5 \%$ of the sample size out of the study area.

\section{Data Processing and Analysis}

The data was entered into Epi-info version 7 and exported to Stata 14 for analysis. Descriptive statistics like frequencies, percentages, and mean were determined and presented in the form of tables and texts. Chi-square assumption was checked. Bi-variable binary logistic regression was carried out first for each variable and those with $p$-value $<0.2$ were taken into the multivariable analysis to control the effect of confounders. Then the multivariable logistic regression model was fitted to identify associated factors for depression, anxiety, and stress. Variables with a $p$-value $<0.05$ 
were reported as significant and declared as associated factors. Crude odds ratio (COR) and adjusted odds ratios (AOR) with a 95\% confidence level were reported to show the strength of the association between the outcome and the independent variables. Hosmer and Lemeshow goodness of fit was used to check the model fitness.

\section{Results}

\section{Socio-Demographic Characteristics of Study Participants}

In this study, 660 (95.2\%) study participants were included. The median age of participants was 32 years with interquartile range (IQR) of 26 to 40 years. Female respondents account for $58.9 \%$ of the study participants. Regarding the marital status of the respondents nearly half (52.4\%) were married and $552(83.6 \%)$ were Orthodox Christian followers. Three hundred sixty-two (54.9\%) of the participants had a family size of less than five (Table 2).

Table 2 Socio-Demographic Characteristics of Gondar Town Adult Population, Northwest Ethiopia, 2020 (N=660)

\begin{tabular}{|c|c|c|}
\hline Variables & Category & $\begin{array}{l}\text { Frequency } \\
\text { (\%) }\end{array}$ \\
\hline Sex & $\begin{array}{l}\text { Male } \\
\text { Female }\end{array}$ & $\begin{array}{l}27 \mid(4 I .1 \%) \\
389(58.9 \%)\end{array}$ \\
\hline Age (in years) & $\begin{array}{l}<26 \\
26-60 \\
\geq 61\end{array}$ & $\begin{array}{l}149(22.6 \%) \\
477(72.3 \%) \\
34(5.1 \%)\end{array}$ \\
\hline Marital status & $\begin{array}{l}\text { Married } \\
\text { Single } \\
\text { Divorced } \\
\text { Widowed }\end{array}$ & $\begin{array}{l}346(52.4 \%) \\
245(37.1 \%) \\
36(5.5 \%) \\
33(5.0 \%)\end{array}$ \\
\hline Religion & $\begin{array}{l}\text { Orthodox } \\
\text { Muslim } \\
\text { Other* }\end{array}$ & $\begin{array}{l}552(83.6 \%) \\
82(12.4 \%) \\
26(3.9 \%)\end{array}$ \\
\hline Occupation & $\begin{array}{l}\text { Unemployed } \\
\text { Government employed } \\
\text { Private employed }\end{array}$ & $\begin{array}{l}324(49.1 \%) \\
203(30.8 \%) \\
133(20.2 \%)\end{array}$ \\
\hline $\begin{array}{l}\text { Educational } \\
\text { status }\end{array}$ & $\begin{array}{l}\text { Unable to read and write } \\
\text { Able to read and write } \\
\text { Primary education } \\
\text { Secondary education and } \\
\text { above }\end{array}$ & $\begin{array}{l}70(10.6 \%) \\
101(15.3 \%) \\
178(27.0 \%) \\
311(49.1 \%)\end{array}$ \\
\hline Family size & $\begin{array}{l}<5 \\
\geq 5\end{array}$ & $\begin{array}{l}362(54.9 \%) \\
297(45.1 \%)\end{array}$ \\
\hline
\end{tabular}

Note: *Catholic and protestant.
One hundred six (16.1\%) respondents had a history of medical illness. Of these, hypertension and diabetes mellitus accounts for $31.19 \%$ and $26.6 \%$, respectively. Two hundred twenty-eight $(34.6 \%)$ respondents had a history of close contact with 2-5 individuals. Two hundred sixteen (32.7\%) individuals reported that other people showed a lot of concern to what they were doing while $76(11.5 \%)$ respondents stated that other people did not show any concern and interest to what they were doing. Getting practical help from friends was perceived as easy by $230(34.9 \%)$ and very difficult by 43 (6.5\%) respondents (Table 3$)$.

Table 3 Clinical Characteristics and Physical Contact History of Gondar Town Adult Population, Northwest Ethiopia, 2020 $(\mathrm{N}=660)$

\begin{tabular}{|c|c|c|}
\hline Variables & Category & $\begin{array}{l}\text { Frequency } \\
\text { (\%) }\end{array}$ \\
\hline History of medical illness & $\begin{array}{l}\text { Yes } \\
\text { No }\end{array}$ & $\begin{array}{l}106(16.1 \%) \\
554(83.9 \%)\end{array}$ \\
\hline Type of medical illness & $\begin{array}{l}\text { Hypertension } \\
\text { Diabetes } \\
\text { Mellitus } \\
\text { HIV } \\
\text { Heart disease } \\
\text { (CHF) } \\
\text { Bronchial } \\
\text { asthma } \\
\text { Cancer } \\
\text { Epilepsy } \\
\text { Other }\end{array}$ & $\begin{array}{l}34(31.2 \%) \\
29(26.6 \%) \\
11(10.1 \%) \\
11(10.1 \%) \\
16(14.8 \%) \\
2(1.9) \\
7(6.5 \%) \\
15(14.0 \%)\end{array}$ \\
\hline Family history of mental illness & $\begin{array}{l}\text { Yes } \\
\text { No }\end{array}$ & $\begin{array}{l}2(0.3 \%) \\
658(99.7 \%)\end{array}$ \\
\hline $\begin{array}{l}\text { Number of people with close } \\
\text { contact }\end{array}$ & $\begin{array}{l}0 \\
\mathrm{I}-2 \\
3-5 \\
>5\end{array}$ & $\begin{array}{l}47(7.1 \%) \\
213(32.3 \%) \\
228(34.6 \%) \\
172(26.1 \%)\end{array}$ \\
\hline $\begin{array}{l}\text { How much concern people give to } \\
\text { you in any situation }\end{array}$ & $\begin{array}{l}\text { No concern } \\
\text { and interest } \\
\text { Little concern } \\
\text { and interest } \\
\text { Uncertain } \\
\text { Some } \\
\text { A lot }\end{array}$ & $\begin{array}{l}76(11.5 \%) \\
83(12.6 \%) \\
81(12.3 \%) \\
204(30.9 \%) \\
216(32.7 \%)\end{array}$ \\
\hline $\begin{array}{l}\text { How easy is it to get practical help } \\
\text { from friends or dorm-mates }\end{array}$ & $\begin{array}{l}\text { Very easy } \\
\text { Easy } \\
\text { Possible } \\
\text { Difficult } \\
\text { Very difficult }\end{array}$ & $\begin{array}{l}18 \mid(27.4 \%) \\
230(34.9 \%) \\
111(16.8 \%) \\
95(14.4 \%) \\
43(6.5 \%)\end{array}$ \\
\hline
\end{tabular}


Table 4 Prevalence and Level of Depression, Anxiety, and Stress Among Gondar Town Population, Northwest Ethiopia, Ethiopia $(\mathrm{N}=660)$

\begin{tabular}{|l|l|l|l|}
\hline Status & Depression & Anxiety & Stress \\
\hline Yes & 211 & 170 & 97 \\
No & 449 & 490 & 563 \\
\hline Level & & & \\
Normal & 449 & 490 & 563 \\
Mild & 59 & 46 & 46 \\
Moderate & 92 & 77 & 40 \\
Severe & 28 & 24 & 7 \\
Extremely severe & 32 & 23 & 4 \\
\hline
\end{tabular}

\section{Substance Use Characteristics of Respondents in Gondar Town}

Lifetime history of cigarette smoking, alcohol drinking, and khat chewing was reported by 46 (7.0\%), 267 (40.4\%), and 78 (11.8\%) participants, respectively. Regarding substance use history in the last 3 months, 31 (4.7\%), 196 (29.7\%), and $45(6.8 \%)$ respondents had a history of cigarette smoking, alcohol drinking, and khat chewing, respectively.

\section{Prevalence of Depression, Anxiety, and Stress Among Gondar Town Population}

The prevalence of depression, anxiety and stress was 32.0\% (95\% CI: 28.4-35.5), 25.8\% (95\% CI: 22.4-29.1), and $14.7 \%$ (95\% CI: 12.0-17.4), respectively. The mean depression, anxiety, and stress score was $7.53 \pm 8.83$ (ranging 0-42), $4.6 \pm 6.35$ (ranging 0-36), and 7.26 \pm 7.33 (ranging 0-40), respectively. Regarding the level of depression, anxiety, and stress, moderate depression 92 $(13.9 \%)$, moderate anxiety $46(7.0 \%)$, and mild stress 46 $(7.0 \%)$ was the most common patterns (Table 4$)$.

\section{Factors Associated with Depression Among Gondar Town Adult Population}

In the bivariate analysis, age, marital status, family size, number of people in close contact, ever cigarette smoking, current cigarette smoking, ever alcohol drinking, ever chat chewing, and current chewing was significant for depression. But, only sex and ever cigarette smoking were significantly associated with depression. The odds of having depression among female adults were $70 \%$ higher $(\mathrm{AOR}=1.7 ; 95 \% \mathrm{CI}: 1.14-2.51)$ than males. Respondents with the lifetime history of cigarette smoking had 2.8 times $(\mathrm{AOR}=2.8,95 \% \mathrm{CI}$ : $1.23-6.28)$ odds of developing depression than non-ever smokers (Table 5).

\section{Factors Associated with Anxiety Among Gondar Town Adult Population}

In the bivariate analysis age, marital status, religion, occupation, educational status, number of person close contacts, history of medical illness, ever cigarette smoking, current cigarette smoking, ever chewing chat, and current chewing chat. However, in the multivariable analysis number of people in close contact, history of medical illness, and being ever smoker were significantly affected anxiety. Study participants with a history of close contact with 1-2 people had 2.3 (AOR=2.3, 95\% CI: 1.01-5.19) higher odds of anxiety than those with a history of no close contact. The odds of anxiety among participants with a history of medical illness were 2.3 times $(\mathrm{AOR}=2.3$, 95\% CI: 1.42-3.76) that of those without a history of medical illness. The odds of anxiety among respondents with a history of lifetime cigarette smoking were 2.8 times (AOR $=2.8,95 \% \mathrm{CI}: 1.23-6.43)$ that of respondents without a history of cigarette smoking (Table 6).

\section{Factors Associated with Stress Among Gondar Town Adult Population}

In the bivariate analysis age, marital status, religion, occupation, family size, history of medical illness, ever cigarette smoking, current cigarette smoking, ever chat chewing, and current chat chewing. The odds of stress among individuals with the occupation of unemployed were 2.1 times (AOR=2.1, 95\% CI: 1.17-3.83) higher than governmental employees. Respondents with a family size of less than five were 1.8 times $(\mathrm{AOR}=1.8,95 \% \mathrm{CI}$ : 1.09-2.81) that of those with a family size of five or more. Study participants with a history of medical illness had 2.2 times (AOR=2.2, 95\% CI: 1.24-3.89) higher odds of stress than those without a history of medical illness (Table 7).

\section{Discussion}

In this study, nearly one-third (32.0\%), about a quarter (25.8\%), and one in every seventh study participants had depression, anxiety, and stress, respectively. Being female and ever smoking negatively affect depression. On the other hand, a history of medical illness, the number of people in close contacts between 1 and 2, and ever smoking are contributing factors for anxiety. Moreover, unemployment, having $<5$ family sizes, and having a history of medical illness were the main contributing factors for stress. 
Table 5 Factors Affecting Depression During COVID-I9 Pandemic Among Gondar Town Population, Northwest Ethiopia, 2020 $(\mathrm{N}=660)$

\begin{tabular}{|c|c|c|c|c|}
\hline \multirow[t]{2}{*}{ Variable } & \multicolumn{2}{|c|}{ Depression } & \multirow[t]{2}{*}{ COR $95 \% \mathrm{CI}$} & \multirow[t]{2}{*}{ AOR 95\% Cl } \\
\hline & Yes & No & & \\
\hline \multicolumn{5}{|l|}{ Sex } \\
\hline Male & 79 & 192 & I & I \\
\hline Female & 132 & 257 & $1.2(0.89-0.74)$ & $81.7(1.14-2.51)$ \\
\hline \multicolumn{5}{|l|}{ Age in years } \\
\hline$<26$ & 47 & 102 & I & I \\
\hline $26-60$ & 149 & 328 & $0.9(0.7-1.46)$ & $0.9(0.59-1.48)$ \\
\hline$\geq 61$ & 15 & 19 & I.7 (0.80-3.6) & $1.9(0.79-4.65)$ \\
\hline \multicolumn{5}{|l|}{ Marital status } \\
\hline Married & 96 & 250 & I & I \\
\hline Single & 84 & 161 & $1.4(0.95-1.93)$ & $1.5(0.98-2.22)$ \\
\hline Widowed and divorced & 31 & 38 & $2.1(1.25-3.60)$ & $1.7(0.95-3.00)$ \\
\hline \multicolumn{5}{|l|}{ Family size } \\
\hline$<5$ & 127 & 235 & $1.4(0.98-1.91)$ & $1.2(0.87-1.78)$ \\
\hline$\geq 5$ & 84 & 213 & I & 1 \\
\hline \multicolumn{5}{|c|}{ Number of people in close contact } \\
\hline 0 & 17 & 30 & I & I \\
\hline $\mathrm{I}-2$ & 87 & 126 & I.2(0.63-2.34) & $1.5(0.77-3.10)$ \\
\hline $3-5$ & 70 & 158 & $0.8(0.40-I .5 \mathrm{I})$ & $1.0(0.49-1.98)$ \\
\hline$>5$ & 37 & 135 & $0.5(0.24-0.97)$ & $0.6(0.30-1.33)$ \\
\hline \multicolumn{5}{|l|}{ Ever smoke } \\
\hline Yes & 29 & 17 & $4.0(2.17-7.55)$ & $2.8(1.23-6.28)$ \\
\hline No & 182 & 432 & I & I \\
\hline \multicolumn{5}{|c|}{ Current cigarette smoking } \\
\hline Yes & 19 & 12 & $3.6(1.7 I-7.57)$ & $1.5(0.57-3.89)$ \\
\hline No & 192 & 437 & I & I \\
\hline \multicolumn{5}{|l|}{ Ever drink alcohol } \\
\hline Yes & 109 & 158 & $2.0(1.4 I-2.74)$ & $1.2(0.70-2.06)$ \\
\hline No & 102 & 291 & I & I \\
\hline \multicolumn{5}{|l|}{ Current drink alcohol } \\
\hline Yes & 84 & 112 & $2.0(1.40-2.82)$ & $1.6(0.90-2.76)$ \\
\hline No & 127 & 337 & & I \\
\hline \multicolumn{5}{|l|}{ Ever chew khat } \\
\hline Yes & 35 & 43 & $1.9(1.16-3.03)$ & $1.2(0.58-2.34)$ \\
\hline No & 176 & 406 & I & I \\
\hline \multicolumn{5}{|l|}{ Current chew khat } \\
\hline Yes & 20 & 25 & $1.8(0.96-3.27)$ & $1.4(0.57-3.20)$ \\
\hline No & 191 & 424 & I & I \\
\hline
\end{tabular}

In the current study, about one in every three study participants had depression. This finding is higher than the study from India which showed that $25 \%$ of study participants were depressed. ${ }^{20}$ The possible reason could be in the former study more than half (54\%) of study participants were under the age of 25 years. Pieces of evidence suggest that age causes body changes that increased the occurrence of depression ${ }^{21}$ and an increase in age is highly correlated with low physical exercise that triggered the development of depression. ${ }^{22,23}$ The second 
Table 6 Factors of Anxiety During COVID-19 Pandemic Among Gondar Town Community, Northwest Ethiopia, 2020 (N=660)

\begin{tabular}{|c|c|c|c|c|}
\hline \multirow[t]{2}{*}{ Variable } & \multicolumn{2}{|c|}{ Anxiety } & \multirow[t]{2}{*}{ COR $95 \% \mathrm{Cl}$} & \multirow[t]{2}{*}{ AOR $95 \% \mathrm{Cl}$} \\
\hline & Yes & No & & \\
\hline \multicolumn{5}{|l|}{ Age in years } \\
\hline$<26$ & 32 & 117 & 1 & 1 \\
\hline $26-60$ & 122 & 355 & $1.3(0.8 \mathrm{I}-1.95)$ & $1.2(0.72-1.99)$ \\
\hline$\geq 61$ & 16 & 18 & $3.3(1.49-7.08)$ & $1.8(0.72-4.65)$ \\
\hline \multicolumn{5}{|l|}{ Marital status } \\
\hline Married & 88 & 258 & $\mathrm{I}$ & 1 \\
\hline Single & 57 & 188 & $0.9(0.6 \mathrm{I}-\mathrm{I} .30)$ & $\mathrm{I}(0.66-1.6 \mathrm{I})$ \\
\hline Widowed and divorced & 25 & 44 & $1.7(0.96-2.9)$ & $\mathrm{I} .5(0.8 \mathrm{I}-2.68)$ \\
\hline \multicolumn{5}{|l|}{ Religion } \\
\hline Orthodox & 137 & 415 & I & 1 \\
\hline Muslim & 27 & 55 & $1.5(0.90-2.5)$ & $1.5(0.82-2.59)$ \\
\hline Others* & 6 & 20 & $0.9(0.36-2.31)$ & $0.9(0.34-2.4)$ \\
\hline \multicolumn{5}{|l|}{ Occupation } \\
\hline Unemployed & 95 & 229 & $1.3(0.90-2.0)$ & $\mathrm{I} .4(0.83-2.21)$ \\
\hline Government employed & 48 & 155 & I & \\
\hline Private employed & 27 & 106 & $0.8(0.48-1.4)$ & $0.7(0.39-1.36)$ \\
\hline \multicolumn{5}{|l|}{ Educational status } \\
\hline Unable to read and write & 22 & 48 & $1.5(0.83-2.6)$ & I.I (0.56-2.17) \\
\hline Able to read and write & 23 & 78 & $0.9(0.55-1.6)$ & $0.8(0.42-1.44)$ \\
\hline Primary education & 51 & 127 & I.3 (0.85-I.9) & $1.2(0.76-0.98)$ \\
\hline Secondary and above & 74 & 237 & 1 & 1 \\
\hline \multicolumn{5}{|c|}{ Number of people close contact } \\
\hline 0 & 10 & 37 & 1 & 1 \\
\hline $1-2$ & 65 & 148 & $1.6(0.76-3.5)$ & $2.3(1.01-5.19)$ \\
\hline $3-5$ & 52 & 176 & I.I $(0.5 \mathrm{I}-2.4)$ & $1.5(0.65-3.42)$ \\
\hline$>5$ & 43 & 129 & $1.2(0.57-2.7)$ & I.6 (0.7I-3.82) \\
\hline \multicolumn{5}{|l|}{ History of medical illness } \\
\hline Yes & 45 & 61 & $2.5(1.64-3.9)$ & $2.3(1.42-3.76)$ \\
\hline No & 125 & 429 & 1 & 1 \\
\hline \multicolumn{5}{|l|}{ Ever smoke } \\
\hline Yes & 24 & 22 & $3.5(1.90-6.4)$ & $2.8(1.23-6.43)$ \\
\hline No & 146 & 468 & I & 1 \\
\hline \multicolumn{5}{|l|}{ Current cigarette smoking } \\
\hline Yes & 15 & 16 & $2.9(1.39-5.9)$ & $1.4(0.54-3.63)$ \\
\hline No & 155 & 474 & 1 & 1 \\
\hline \multicolumn{5}{|l|}{ Ever chew khat } \\
\hline Yes & 29 & 49 & $1.9(1.1-3.0)$ & I.I (0.5I-2.23) \\
\hline No & $|4|$ & $44 I$ & 1 & \\
\hline \multicolumn{5}{|l|}{ Current chewing khat } \\
\hline Yes & 17 & 28 & $1.8(0.98-3.44)$ & $1.2(0.53-0.95)$ \\
\hline No & 153 & 462 & $\mathrm{I}$ & \\
\hline
\end{tabular}

Note: *Catholic and protestant. 
Table 7 Factors Affecting Stress During COVID-19 Pandemic Among Gondar Town Population, Northwest Ethiopia, 2020 (N=660)

\begin{tabular}{|c|c|c|c|c|}
\hline \multirow{2}{*}{ Variable } & \multicolumn{2}{|c|}{ Stress } & \multirow[t]{2}{*}{ COR 95\% Cl } & \multirow[t]{2}{*}{ AOR 95\% Cl } \\
\hline & Yes & No & & \\
\hline \multicolumn{5}{|l|}{ Age in years } \\
\hline$<26$ & 17 & 132 & I & I \\
\hline $26-60$ & 70 & 407 & $1.3(0.76-2.35)$ & $1.2(0.64-2.30)$ \\
\hline$\geq 61$ & 10 & 24 & $3.2(1.32-7.91)$ & $1.6(0.55-0.73)$ \\
\hline \multicolumn{5}{|l|}{ Marital status } \\
\hline Married & 49 & 297 & I & I \\
\hline Single & 31 & 214 & $0.9(0.54-1.42)$ & $0.9(0.56-1.69)$ \\
\hline Widowed and divorced & 17 & 52 & $2(1.06-3.70)$ & $1.6(0.80-3.09)$ \\
\hline \multicolumn{5}{|l|}{ Religion } \\
\hline Orthodox & 76 & 476 & I & I \\
\hline Muslim & 15 & 67 & $1.4(0.76-2.58)$ & I.I (0.54-2.22) \\
\hline Others* & 6 & 20 & $1.9(0.73-4.82)$ & $2.1(0.80-5.75)$ \\
\hline \multicolumn{5}{|l|}{ Occupation } \\
\hline Unemployed & 6 & 268 & $1.8(1.06-0.09)$ & $2.1(1.17-3.83)$ \\
\hline Government employed & 21 & 182 & 1 & 1 \\
\hline Private/self-employee & 20 & 113 & $1.5(0.80-2.95)$ & $1.7(0.83-3.40)$ \\
\hline \multicolumn{5}{|l|}{ Family size } \\
\hline$<5$ & 60 & 302 & $1.4(0.90-2.17)$ & I.8 (I.09-2.8I) \\
\hline$\geq 5$ & 37 & 260 & I & I \\
\hline \multicolumn{5}{|c|}{ History of medical IIIness } \\
\hline Yes & 27 & 79 & $2.4(1.42-3.9)$ & $2.2(1.24-3.89)$ \\
\hline No & 70 & 484 & 1 & 1 \\
\hline \multicolumn{5}{|l|}{ Ever smoke } \\
\hline Yes & 15 & 31 & $3.1(1.62-6.07)$ & $\mathrm{I} .6(0.65-4.1 \mathrm{I})$ \\
\hline No & 82 & 532 & 1 & \\
\hline \multicolumn{5}{|c|}{ Current cigarette smoking } \\
\hline Yes & 11 & 20 & $3.5(1.6 \mathrm{I}-7.50)$ & $2.3(0.82-6.47)$ \\
\hline No & 86 & 543 & 1 & 1 \\
\hline \multicolumn{5}{|l|}{ Ever chew khat } \\
\hline Yes & 21 & 57 & $2.5(I .4 I-4.27)$ & $2.0(0.90-4.65)$ \\
\hline No & 76 & 506 & 1 & \\
\hline \multicolumn{5}{|l|}{ Current chewing khat } \\
\hline Yes & 11 & 34 & $2.0(0.97-4.07)$ & $1.0(0.38-2.72)$ \\
\hline No & 86 & 529 & I & \\
\hline
\end{tabular}

Note: *Catholic and protestant.

reason could be in the former study more than $86 \%$ of study participants attained at least graduate-level study. This finding is fostered by a randomized controlled trial that showed behavioral and education therapy has a significant role in improving the health status of the participants and minimize the burden of depression. ${ }^{24}$ However, in the current study, only small proportion of respondents attained education. Besides, the current finding is higher than the study from Spain (18.7\%). The possible explanation could be in the previous study depression was measured within 1 week preceding the survey and used Impact of Events Scale-Revised (IES-R) tool which is a 22-item self-administered questionnaire. ${ }^{25}$ However, in the recent study depression was measured using the DASS-21 tool within weeks preceding the survey. According to works of literature using DASS-21 is 
a more appropriate and measuring depression with a sensitivity and specificity of $86 \%$ and $64 \%$, respectively. ${ }^{26}$ In contrast, the IES-R tool is mainly recommended in people experiencing trauma and less frequently advisable in assessing depression without a crisis. ${ }^{27}$

In this study, one in every fourth respondent had anxiety. This finding is consistent with a study from China $(24 \%)^{28}$ and Mexico $22.6 \% .^{29}$ In contrast, this finding is lower than a study done from the United States which showed that $45.4 \%$ of participants had anxiety. The difference is attributed to a measurement difference. In the former study, Generalized Anxiety Disorder-7 (GAD-7) was used and in the current study, DASS-21 was used. Evidence spotted out GAD-7 is an appropriate and valid tool for measuring anxiety among students, but its use in health care and research is limited. ${ }^{30}$ On the other hand, the current study is higher than the study done in Jordan, only $8 \%$ of the general population had anxiety symptoms. ${ }^{31}$ The possible variation could be the use of different tools in which the former study used GAD-7 and the current study used DASS-21 for measuring anxiety.

Nearly $15 \%$ of the study participants had stress in the current study. This finding is lower than a study from Spain which showed that $41 \%$ of study participants had stress. $^{25}$ This could be Spain was the second most affected country during the early phase of the pandemic at the end of February 2020 by case and death. However, the disease does not spread across the globe and it introduced to Ethiopia since March 4. On the other hand, this finding is higher than a study from the general population in India which showed that $11 \%$ of the population had stress. ${ }^{20}$

Being female increased the odds of depression compared to male counterparts. This finding is in agreement with a study done among the general population in Mexico $^{29}$ and China. ${ }^{17}$ This might be because females are more likely to develop depression due to the intersect effect of genetic, biological, hormonal, social, and psychological factors. ${ }^{32}$ The second reason could be the presence of androgen receptors in males that may give protection, ${ }^{33}$ and testosterone hormone does not cycle as estrogen in women that has also a protection in males. Besides, in the male brain testosterone is converted into estrogen that mediates protective actions through estrogen receptors. ${ }^{34}$

Moreover, smokers were at higher odds of developing depression and anxiety than non-smokers. This finding is supported by a study from Australia. ${ }^{35}$ This is because smokers are at higher risk of developing respiratory problems like lung cancer and Chronic Obstructive
Pulmonary Disease (COPD) that worsen the effect of COVID-19. Consequently, they will develop depression and anxiety. Besides, it is due to the fact that smoking reduces the dopamine hormone released in the brain that triggers happiness or pleasure. ${ }^{36,37}$ Hence, they become easily depressed and it gives a clue to offer proper support for these vulnerable populations to minimize its burden.

Having more number of close contacts was associated with higher odds of anxiety than having no contact. This finding is concurrent with a study from Mexico. ${ }^{29}$ This could be because of possible misinformation or information overload when there was a large number of close contacts. ${ }^{38}$ Likewise, more close contact increases the likelihood of exposing the deadly virus. Therefore, it is highly recommended to apply precaution measures like social distancing, frequent hand washing, using masks, and sanitizer.

In this study, unemployed study participants were at higher odds of developing stress. This could be because unemployment causes financial crises due to the national lockdown and family members may be unable to cover all the expenses. A piece of evidences suggest that family economic status negatively affects mental health status. ${ }^{39}$ Besides, the finding from Spain noted that because of unemployment, economic crises was the most common cause of suffering that causes stress. ${ }^{25}$

In this study, participants with chronic diseases had higher odds of anxiety and stress than the counterparts. This finding is in line with a study conducted in Israel, ${ }^{40}$ Spain, ${ }^{26}$ and Greek. ${ }^{27}$ This is because patients with chronic diseases have an increased risk of complications and mortality from COVID-19. ${ }^{41}$ As a result, patients with chronic diseases are getting anxious and stressed. Hence, it is good to provide psychological support, particularly to vulnerable groups to halt the psychological effect and to keep the adherence to their treatment for the chronic diseases as well.

This finding can be generalized to the Gondar town population. However, it has the following limitations. The first one is the finding was conducted in Gondar town only and may not be generalized to the whole of Ethiopia and other low- and middle-income countries. Secondly, it lacks the temporal relationships between the exposure and outcome variables because of the cross-sectional nature of the data. Finally, the self-reported nature of the questionnaires administered and the lack of information about substance use, other than alcohol, khat and smoke were the other limitations of this study. 
The findings of this study have paramount importance to the public and clinical setups. In this study, magnitude and factors affecting depression, anxiety, and stress were well spotted. Hence, persons with the problem will identify early which is helpful to get early treatment. Besides, the finding of the study highlighted the need to improve mental health care planning, treatment, and design preventive measures.

\section{Conclusion}

In this study, the overall depression, anxiety, and stress were significantly high. There are number of predictors associated with depression, anxiety, and stress. Designing and implementing tailored strategies with COVID-19 prevention and control could be supremely important to reduce these problems in the community.

\section{Abbreviations}

AOR, adjusted odds ratio; BSc, Bachelor of Science; CI, confidence interval; COVID-19, coronavirus disease 19; COR, crude odds ratio; DASS-21, Depression Anxiety Stress scale; IES-R, Impact of Events Scale-Revised; GAD-7, Generalized Anxiety Disorder; IQR, interquartile range; WHO, World Health Organization.

\section{Data Sharing Statement}

Data will be available upon request from the corresponding author.

\section{Ethical Approval and Consent to Participate}

Ethical approval was obtained from the institutional review board of the University of Gondar. Similarly, we got permission from the regional health authorities to conduct this study in the community. Verbal informed consent was approved by the Institutional Review Board of the University of Gondar, and that this study was conducted in accordance with the Declaration of Helsinki. Verbal informed consent was taken after describing the purpose of the research briefly; those individuals who refused to participate were excluded. Sanitizer and surgical face masks were used to prevent from COVID-19 infection. The confidentiality of the study participants was protected.

\section{Acknowledgments}

Firstly, we would like to forward our kindest regards to our study participants. We extend our thanks to data collectors and supervisors without them the study will not be materialized. At last but not least, the authors would forward great thanks to the University of Gondar for financial support.

\section{Author Contributions}

All authors made substantial contributions to conception and design, acquisition of data, or analysis and interpretation of data; took part in drafting the article or revising it critically for important intellectual content; agreed to submit to the current journal; gave final approval of the version to be published; and agree to be accountable for all aspects of the work.

\section{Funding}

Minimal funding was received from the University of Gondar for data collection.

\section{Disclosure}

The authors report no conflicts of interest in this work.

\section{References}

1. Qiu SJ, Zhao B, Wang M, et al. A nationwide survey of psychological distress among Chinese people in the COVID-19 epidemic: implications and policy recommendations. Gen Psychiatry. 2020;33 (2). doi:10.1136/gpsych-2020-100213.

2. control ECoDPa. Novel Coronavirus Disease 2019 (COVID-19) Pandemic: Increased Transmission in the EU/EEA and the UKSixth Update 12 March 2020. European Center of Disease Prevention and control; 2019:6.

3. Team Cd. COVID-19 Dashboard by the Center for Systems Science and Engineering (CSSE) at Johns Hopkins University. 2020.

4. ISAC. Briefing Note on Addressing Mental Health and Psychosocial Aspects of COVID-19 Outbreak. 2020:1

5. Organization IL. COVID-19 and the World of Work: Impact and Policy Responses. 2020.

6. Brooks SK, Webster RK, Smith LE, et al. The psychological impact of quarantine and how to reduce it: rapid review of the evidence. Lancet. 2020;395(10227):912-920. doi:10.1016/S0140-6736(20) 30460-8

7. Qiu J, Shen B, Zhao M, Wang Z, Xie B, Xu Y. A nationwide survey of psychological distress among Chinese people in the COVID-19 epidemic: implications and policy recommendations. Gen Psychiatry. 2020;33(2):100213. doi:10.1136/gpsych-2020-100213

8. Liu N, Zhang F, Wei C, et al. Prevalence and predictors of PTSS during COVID-19 outbreak in China hardest-hit areas: gender differences matter. Psychiatry Res. 2020;287:112921. doi:10.1016/j. psychres.2020.112921

9. Nicola D. Serum 25-hydroxyvitamin D levels and psychological distress symptoms in patients with affective disorders during the COVID-19 pandemic. Psychoneuroendocrinology. 2020.

10. Salari N, Hosseinian-Far A, Jalali R, et al. Prevalence of stress, anxiety, depression among the general population during the COVID-19 pandemic: a systematic review and meta-analysis. Glob Health. 2020;16(1):57. doi:10.1186/s12992-020-00589-w

11. Huang Y, Zhao N. Generalized Anxiety Disorder, Depressive Symptoms and Sleep Quality During COVID-19 Epidemic in China: A Web-Based Cross-Sectional Survey. 2020. 
12. Rodríguez-Rey R, Garrido-Hernansaiz H, Collado S. Psychological impact and associated factors during the initial stage of the coronavirus (COVID-19) pandemic among the general population in Spain. Open Access. 2020;11.

13. Conversano C, Marchi L, Miniati M. Psychological distress among healthcare professionals involved in the COVID-19 emergency: vulnerability and resilience factors. Clin Neuropsychiatry. 2020b;17:94-96.

14. Wilkinson RG, Marmot MG. Social Determinants of Health: The Solid Facts. 2nd ed. Geneva: World Health Organization; 2003.

15. Marazziti D, Pozza A, Di Giuseppe M, Conversano C. The psychosocial impact of COVID-19 pandemic in Italy: a lesson for mental health prevention in the first severely hit European country. Psychol Trauma. 2020;12(5):531-533. doi:10.1037/tra0000687

16. Di Nicola M, Dattoli L, Moccia L, et al.. Serum 25-hydroxyvitamin D levels and psychological distress symptoms in patients with affective disorders during the COVID-19 pandemic. Psychoneuroendocrinology. 2020;122:104869

17. Wang $C$, Pan $R$, Wan $X$, et al. Immediate psychological responses and associated factors during the initial stage of the 2019 coronavirus disease (COVID-19) epidemic among the general population in China. Int J Environ Res Public Health. 2020;17(5).

18. Lovibond PF, Lovibond SH. The structure of negative emotional states: comparison of the depression anxiety stress scales (DASS) with the beck depression and anxiety inventories. Behav Res Ther 1995;33(3):335-343. doi:10.1016/0005-7967(94)00075-U

19. Humeniuk R, Ali R, Babor TF, et al. Validation of the alcohol, smoking and substance involvement screening test (ASSIST). Addiction. 2008;103(6):1039-1047. doi:10.1111/j.1360-0443.2007.02114.x

20. Verma S, Mishra A. Depression, anxiety, and stress and socio-demographic correlates among general Indian public during COVID-19. Int J Soc Psychiatry. 2020;20764020934508.

21. Blazer DG. Depression in late life: review and commentary. J Gerontol a Biol Sci Med Sci. 2003;58(3):249-265.

22. Verrusio W, Renzi A, Cecchetti F, et al. The effect of a physical training with the use of an exoskeleton on depression levels in institutionalized elderly patients: a pilot study. $J$ Nutr Health Aging. 2018;22(8):934-937. doi:10.1007/s12603-018-1044-2

23. Turner AP, Hartoonian N, Hughes AJ, et al. Physical activity and depression in MS: the mediating role of behavioral activation. Disabil Health J. 2019;12(4):635-640. doi:10.1016/j.dhjo.2019.04.004

24. Richards DA, Ekers D, McMillan D, et al. Cost and outcome of behavioural activation versus cognitive behavioural therapy for depression (COBRA): a randomised, controlled, non-inferiority trial. Lancet. 2016;388(10047):871-880. doi:10.1016/S01406736(16)31140-0

25. Rodríguez-Rey R, Garrido-Hernansaiz H, Collado S. Psychological impact and associated factors during the initial stage of the coronavirus (COVID-19) pandemic among the general population in Spain. Front Psychol. 2020;11:1540. doi:10.3389/fpsyg.2020.01540

26. González-Sanguino C, Ausín B, Castellanos M, et al. Mental health consequences during the initial stage of the 2020 Coronavirus pandemic (COVID-19) in Spain. Brain Behav Immun. 2020;87:172-176. doi:10.1016/j.bbi.2020.05.040
27. Louvardi M, Pelekasis P, Chrousos GP, Darviri C. Mental health in chronic disease patients during the COVID-19 quarantine in Greece. Palliat Support Care. 2020;1-6.

28. Elhai JD, Yang H, McKay D, Asmundson GJG. COVID-19 anxiety symptoms associated with problematic smartphone use severity in Chinese adults. J Affect Disord. 2020;274:576-582. doi:10.1016/j. jad.2020.05.080

29. Cortés-álvarez NY, Piñeiro-Lamas R, Vuelvas-Olmos CR. Psychological effects and associated factors of COVID-19 in a Mexican sample. Disaster Med Public Health Prep. 2020;1-12. doi: $10.1017 /$ dmp.2020.495

30. Kim YE, Lee B. The psychometric properties of the patient health questionnaire-9 in a sample of Korean university students. Psychiatry Investig. 2019;16(12):904-910. doi:10.30773/pi.2019.0226

31. Naser AY, Dahmash EZ, Al-Rousan R, et al. Mental health status of the general population, healthcare professionals, and university students during 2019 coronavirus disease outbreak in Jordan: a cross-sectional study. Brain Behav. 2020;10(8):e01730. doi:10.1002/ brb3.1730

32. Albert PR. Why is depression more prevalent in women? J Psychiatry Neurosci. 2015;40(4):219-221. doi:10.1503/jpn.150205

33. McEwen BS, Milner TA. Hippocampal formation: shedding light on the influence of sex and stress on the brain. Brain Res Rev. 2007;55 (2):343-355. doi:10.1016/j.brainresrev.2007.02.006

34. Gillies GE, McArthur S. Estrogen actions in the brain and the basis for differential action in men and women: a case for sex-specific medicines. Pharmacol Rev. 2010;62(2):155-198. doi:10.1124/ pr.109.002071

35. Stanton R, To QG, Khalesi S, et al. Depression, anxiety and stress during COVID-19: associations with changes in physical activity, sleep, tobacco and alcohol use in Australian adults. Int $J$ Environ Res Public Health. 2020;17(11):11. doi:10.3390/ijerph17114065

36. Munafò MR, Araya R. Cigarette smoking and depression: a question of causation. Br J Psychiatr. 2010;196(6):425-426. doi:10.1192/bjp. bp.109.074880

37. Boden JM, Fergusson DM, Horwood LJ. Cigarette smoking and depression: tests of causal linkages using a longitudinal birth cohort. Br J Psychiatr. 2010;196(6):440-446.

38. Burtscher J, Burtscher M, Millet GP. (Indoor) isolation, stress and physical inactivity: vicious circles accelerated by Covid-19? Scand J Med Sci Sports. 2020;30(8):1544-1545. doi:10.1111/sms.13706

39. Rehman U, Shahnawaz MG, Khan NH, et al. Depression, anxiety and stress among Indians in times of Covid-19 lockdown. Community Ment Health J. 2020;1-7.

40. Horesh D, Kapel Lev-Ari R, Hasson-Ohayon I. Risk factors for psychological distress during the COVID-19 pandemic in Israel: loneliness, age, gender, and health status play an important role. $\mathrm{Br}$ J Health Psychol. 2020;25(4):925-933. doi:10.1111/bjhp.12455

41. Willis MD, Robertson NP. Multiple sclerosis and the risk of infection: considerations in the threat of the novel coronavirus, COVID-19/SARS-CoV-2. J Neurol. 2020;267(5):1567-1569. doi:10.1007/s00415-020-09822-3
Risk Management and Healthcare Policy is an international, peerreviewed, open access journal focusing on all aspects of public health, policy, and preventative measures to promote good health and improve morbidity and mortality in the population. The journal welcomes submitted papers covering original research, basic science, clinical \& epidemiological studies, reviews and evaluations, guidelines, expert opinion and commentary, case reports and extended reports. The manuscript management system is completely online and includes a very quick and fair peer-review system, which is all easy to use. Visit http://www.dovepress.com/testimonials.php to read real quotes from published authors. 